\title{
Effect of stress relieving heat treatment on surface topography and dimensional accuracy of incrementally formed grade 1 titanium sheet parts
}

\author{
Amar Kumar Behera ${ }^{1,2} \cdot$ Hengan Ou ${ }^{1}$
}

Received: 13 August 2015 / Accepted: 4 March 2016/Published online: 12 April 2016

(C) The Author(s) 2016. This article is published with open access at Springerlink.com

\begin{abstract}
The forming of parts with an optimized surface roughness and high dimensional accuracy is important in many applications of incremental sheet forming (ISF). To realize this, the effect of stress relieving heat treatment of grade1 Ti parts performed before and after forming on the surface finish and dimensional accuracy was studied. It was found that heat treatment at a temperature of $540{ }^{\circ} \mathrm{C}$ for $2 \mathrm{~h}$ improves the surface finish of formed parts resulting in a surface with little or no visible tool marks. Additionally, it improves the dimensional accuracy of parts after unclamping from the rig used for forming, in particular, that of parts with shallow wall angles (typically $<25^{\circ}$ ). It was also noted that post-forming heat treatment improves the surface finish of parts. The surface topography of formed parts was studied using interferometry to yield areal surface roughness parameters and subsequently using secondary electron imaging. Back-scatter electron microscopy imaging results coupled with energy-dispersive Xray (EDX) analysis showed that heat treatment prior to forming leads to tool wear as indicated by the presence of $\mathrm{Fe}$ in samples. Furthermore, post-forming heat treatment prevents curling up of formed parts due to compressive stresses if the formed part is trimmed.
\end{abstract}

Amar Kumar Behera

a.k.behera@leeds.ac.uk

Hengan Ou

h.ou@nottingham.ac.uk

1 Faculty of Engineering, Division of Materials, Mechanics and Structures, University of Nottingham, Nottingham NG7 2RD, UK

2 Present address: School of Mechanical Engineering, University of Leeds, Leeds LS2 9JT, UK
Keywords Stress relieving · Heat treatment - Titanium · Incremental sheet forming $\cdot$ Surface roughness $\cdot$ Trimming

\section{Introduction}

Titanium is the material of choice for a number of bio-medical and commercial applications such as jet engines, aircrafts, sporting goods, surgical instruments, implants, and racing. $[1,2]$ This is primarily due to its properties such as lightweight, strength, corrosion resistance, and bio-compatibility [2]. Nearly 50 grades of titanium are currently designated and used, of which the first four grades consist of unalloyed titanium with varying amounts of oxygen content [3].

Given the wide range of critical applications involving titanium and its alloys, a tight control on the surface quality and topography is often desirable. In particular, Nishiguchi et al. [4] observed that the bone-bonding ability of titanium is affected by the surface topology of the implant, and both alkali and heat treatment are essential for preparing bioactive titanium. Likewise, Wennerberg et al. [5] laid out guidelines for the topographic evaluation of implant surfaces to facilitate a systematic control of the surface quality for implants. In another study on commercially pure titanium implants placed in rabbit tibiae and made by blasting with fine and coarse particles of aluminum oxide, it was found that a highly increased surface roughness compared to a moderately increased one is disadvantageous for bone tissue [6].

While titanium sheets can be formed into desired shapes using conventional sheet forming techniques such as stamping, forging, deep drawing, and hydroforming, the emergence of flexible sheet forming processes such as incremental sheet forming (ISF) has facilitated a decreased lead time to manufacture [7]. Incremental sheet forming is available in many variants such as single point incremental forming 
(SPIF), two point incremental forming (TPIF) and use of a partial or full die [8]. The essential concept involves deforming a flat sheet in incremental steps, typically using a cylindrical tool with a hemispherical end, following a tool path on a computer numeric controlled (CNC) machine [9]. Surface roughness is a key area of concern in ISF, as the surface finish on parts is dependent on a number of factors such as the tool feed rate, the step down distance between successive contours, lubrication, tool diameter, and wall angle [7, 10, 11].

Hamilton et al. [12] studied the surface and structural consequences of increasing the feed rate and tool rotational speed in SPIF. They concluded that an orange peel effect was observed on the non-contact surface giving it a rough look, which could be characterized by an equivalent roughness parameter defined as a weighted average of the arithmetic average roughness, $R_{a}$ and the average peak to valley height, $R_{z}$. It was also shown that SPIF could be done at high speeds, as a result of this work. Later, Ham et al. [13, 14] suggested that it was more useful to use areal surface texture parameters in evaluating surface texture and topography in SPIF and compared surfaces produced using two different types of tools, acetal, and carbide. It was found that the acetal tool produces rougher surfaces than the carbide tool, but with more isotropy.

In addition to surface topography, one of the key challenges in ISF is to form parts with high accuracy [7, 8]. Approaches to improve the accuracy have included toolpath optimization techniques [15-18], use of in-process heating techniques such as laser support or electric heating to soften the material and thereby reduce spring back and plastic deformation [19, 20], feature analysis based techniques $[21,22]$, use of tooling strategies [23] etc. Limited improvement in accuracy of titanium sheet parts was demonstrated for a TPIF process using laser support by Göttmann et al. [24] and for SPIF by compensating part geometry by Behera et al. [25].

While the efforts to characterize and optimize surface roughness and improve dimensional accuracy in SPIF have met with some success, more techniques need to be forthcoming to meet stringent industrial specifications in a number of applications. In particular, the effect of heat treatment strategies on surface topography has not been looked at in depth. To address the current limitations, and in particular, to meet the requirements of forming bio-medical implants using titanium, the current study involved looking at the effect of stressrelieving heat treatment on part surface quality and accuracy. Titanium sheet blanks (grade 1) of size $140 \mathrm{~mm} \times 140 \mathrm{~mm}$ with a thickness of $0.5 \mathrm{~mm}$ were heat treated at a temperature recommended for stress relieving [26] and then used for forming parts with planar, ruled, and freeform features. The effect on surface topography was analyzed using areal surface roughness measures, and the effect of dimensional accuracy was observed. In addition, parts were formed without heat treatment and subjected to a heat treatment step subsequently, and the effect on surface roughness and dimensional accuracy has been studied. The results were compared to parts formed without any heat treatment steps before or after forming. In order to understand the underlying physical phenomena that explain the observations relating to surface topography, scanning electron microscopy (SEM) imaging of the formed surfaces was carried out in conjunction with EDX analysis. This was followed by residual stress measurements carried out using XRD to explain the changes in dimensional accuracy. These measurements further prompted the analysis of accuracy on trimming the formed parts, the results of which are presented next.

\section{Experimental methodology}

Semiatin et al. [27] mention that titanium and its alloys are considered among the most difficult to process as there is a need to hot work these materials to obtain the desired microstructure giving it the mechanical properties that are required in critical applications. It is also well understood that stressrelieving treatments in titanium help reduce the undesirable residual stresses that result from processes such as hot forging, cold forming followed by straightening, and asymmetric machining. [26]. For pure Ti (grades 1-4), the recommended temperature range for stress relief heat treatment is 480 $595^{\circ} \mathrm{C}$ for a time span of $1 / 4-4 \mathrm{~h}$ followed by either air cooling or slow cooling [26]. In particular, it has been noted that stress relieving for $2 \mathrm{~h}$ at $540{ }^{\circ} \mathrm{C}$ is useful to machine thin $\mathrm{Ti}$ alloy rings with higher precision and faster production rate [26]. It is also important to relieve stress at a temperature where an undesirable amount of precipitation or strain aging can be avoided [26].

\subsection{Blank preparation}

The sheet blanks used in this study were commercially pure Ti grade 1 sheets of $0.5 \mathrm{~mm}$. The plates were heated to a temperature of $540{ }^{\circ} \mathrm{C}$ at a fixed rate of $20{ }^{\circ} \mathrm{C} \mathrm{min}^{-1}$ in a Carbolite electric furnace with a maximum operating temperature specification of $1150^{\circ} \mathrm{C}$, kept at that temperature for $2 \mathrm{~h}$, and then cooled to room temperature in the furnace. This cycle was also used for non-heat-treated formed parts, which were stress relieved post forming. It may also be noted that the rate of cooling from the temperatures used for stress relieving is not critical, although uniformity of cooling should be maintained [26]. It may also be noted that the objective of these studies was not to optimize the duration of heat treatment, temperature, or rate and hence no design of experiments was used to set these parameters. There were three types of specimens that were made in these studies: (i) sheets that were stress relieved and then formed using SPIF, (ii) sheets that were not stress relieved prior to forming but were subjected to the above cycle 
after forming, and (iii) sheets that were not stress relieved either before or after forming.

\subsection{Incremental forming conditions}

The parts were formed on a 3 -axis Hurco VM1 CNC milling machine (working range: $660 \mathrm{~mm} \times 406 \mathrm{~mm} \times 508 \mathrm{~mm}$ ) using a cylindrical CNC stylus with hemi-spherical end made of $\mathrm{H} 13$ tool steel of $5 \mathrm{~mm}$ radius at a feed rate of $2 \mathrm{~m} / \mathrm{min}$ and no tool rotation. A soft low melting point paste lubricant, Rocol RTD compound was used to reduce the friction in the process. The lubricant was applied as a thin layer on the flat blank prior to forming so as to cover the entire surface of the blank. The sheets were clamped to the rig by using four clamping plates which were bolted to the rig. As the sheets came protected with a layer of polymeric cover which ensured that the surfaces were clean, no additional surface treatment operations were needed. Figure 1 illustrates the setup used. Backing plates conforming to the top contour of the part to be formed were used in all tests, and the distance between successive contours was set at a uniform scallop height of $0.05 \mathrm{~mm}$. The scallop height is the small cusp of material that projects out of the formed surface when the tool steps from one contour to the next [28].

The geometries formed in this study are: (i) elliptical draft surface with wall angle of $15^{\circ}$, (ii) truncated cone with wall angle of $20^{\circ}$, (iii) pyramid with wall angle of $25^{\circ}$, and (iv) cranial implant [29]. The elliptical draft and cone represent ruled surfaces, the pyramid is made of planar features and the cranial implant is a freeform surface. Figure 2 shows the cross-sections of these parts along with isometric views. In addition to these parts, additional parts with ruled and planar features (cones, elliptical drafts, and pyramids with wall angles between $30^{\circ}$ and $50^{\circ}$ ) were also formed to additionally validate the conclusions from the four benchmark cases. In all, 16 parts were formed with different heat treatment settings for each part, as detailed in Table 1. Numerical results for parts 1-

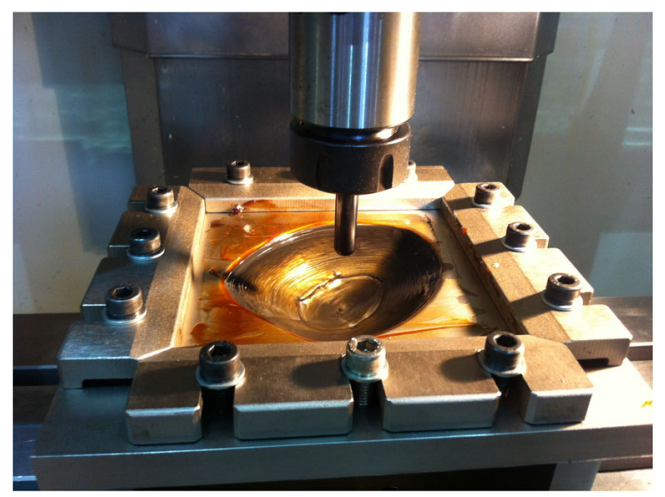

Fig. 1 Setup used for forming the parts showing the hemispherical tool, formed implant part with lubricant visible on the surface and rig clamped with clamping plates on four sides
10 are given in section 3 . The results from part 11-16 were used to confirm the conclusions from the analysis of the results of parts $1-10$.

\section{Results}

The formed parts were analyzed for the effect of stress relieving heat treatment on the surface topography and geometric accuracy. Residual stress measurements using X-ray diffraction (XRD) were carried out to evaluate the effect of heat treatment on geometric accuracy and find out whether any phase transformations occurred during the heat treatment process that explain the differences in surface topography and spring back behavior during forming. Imaging using scanning electron microscopy (SEM) was used to observe the surface morphology more closely and also make relevant conclusions from the elemental distribution on the part surfaces using EDX analysis.

\subsection{Effect on surface topography}

Surface topography mapping for the parts formed in this study was carried out using a Bruker ContourGT-I 3D interferometer, which has a vertical resolution of approximately $0.15 \mathrm{~nm}$ and a lateral resolution of $4 \mu \mathrm{m}$. An objective lens with $5 \times$ magnification and white light illumination was used. For precision, the repeatability of the root mean squared height measured 30 times on a reference artifact is usually used. The 1 sigma standard deviation of that quantity is typically found as $<0.01 \mathrm{~nm}$ for the ContourGT-I system.

For each part, five overlapping surface measurements were made, each with dimensions $1.2 \mathrm{~mm} \times 0.9 \mathrm{~mm}$, which were stitched together to form the area of size $2 \mathrm{~mm} \times 2 \mathrm{~mm}$ for analysis. The surface texture parameters determined within this research are areal parameters as defined within ISO 25178-2 [30]. They were calculated within the software, Vision64, provided by Bruker by filtering to remove short wavelengths (Sfilter) and another filter to remove form, termed as F-operation. The F-operation removes linear tilt by fitting a plane of the form "ax + by $+c=z$ " and subtracting it from surface measurements. As the maximum sampling distance in these studies was $600 \mathrm{~nm}$, a Gaussian regression filter with a S-filter nesting index value of $2 \mu \mathrm{m}$ is used to implement the S-filter, based on the guidelines in ISO 25178-3 [30].

Four height parameters and two spatial parameters were chosen to characterize the surfaces studied in this work. The height parameters used are Sa (average roughness), Sq (root mean square height), Sz (maximum height), Ssk (skewness), and Sku (kurtosis), while the spatial parameters used were Sal and Str. Sal gives a measure of the distance over the surface in an optimum direction such that the new location has minimal correlation 
Fig. 2 Geometries formed using SPIF for studying the effect of heat treatment on surface roughness and part accuracy showing a ellipse draft $\mathbf{b}$ cone $\mathbf{c}$ pyramid $\mathbf{d}$ cranial implant with sections shown below an isometric view taken along the dotted line AA' for parts $\mathbf{a}-\mathbf{c}$ and along $\mathrm{AA}^{\prime}$ and $\mathrm{BB}$ ' for (d)

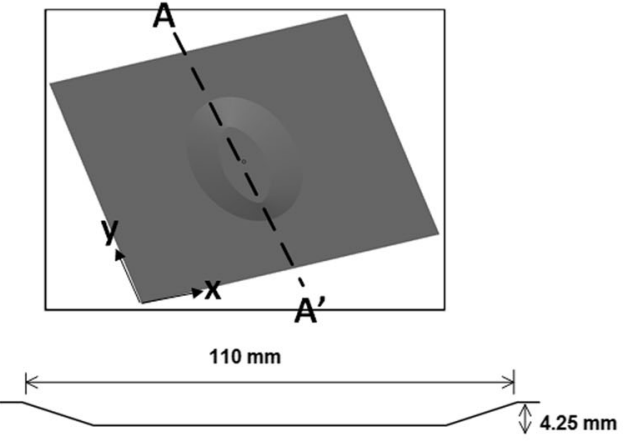

(a)

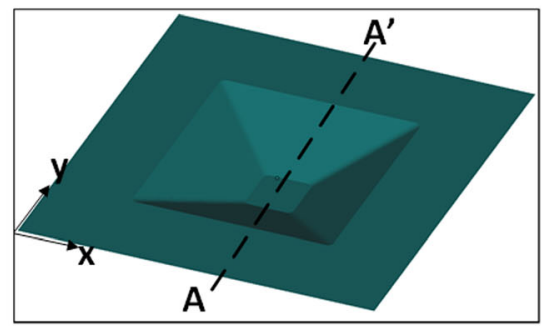

$112.5 \mathrm{~mm}$

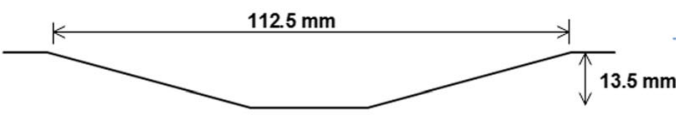

(c)
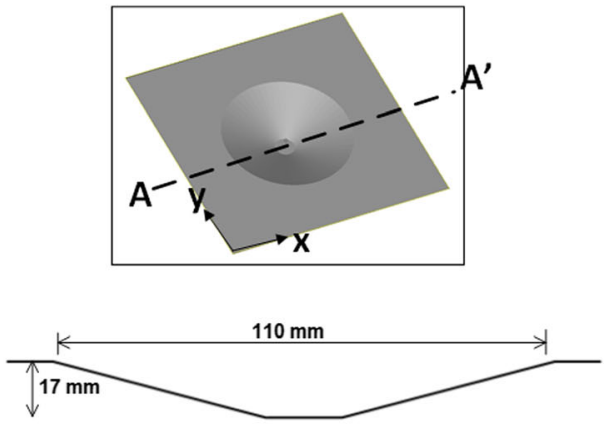

(b)
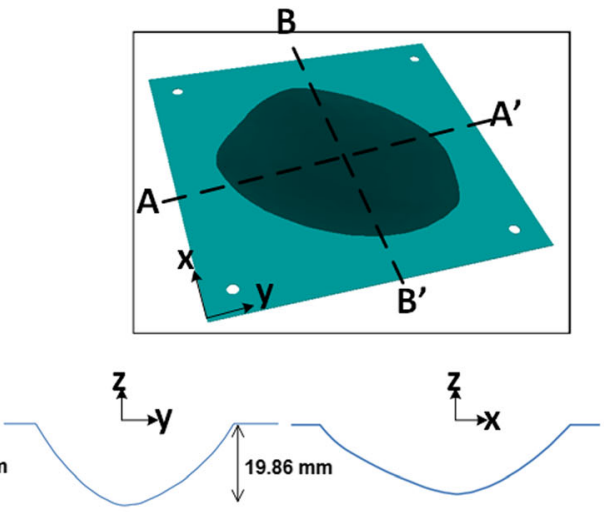

(d) with the original location, which signifies the length over which the correlation between two locations decays fastest [31]. Str is a measure of the spatial isotropy or directionality of the surface texture and calculated as the ratio of the length of the fastest decay to the length of the slowest decay in any direction [31]. A value of Str close to zero indicates a highly anisotropic surface while a value close to 1 indicates a highly isotropic surface.

Table 1 Details of formed parts

\begin{tabular}{|c|c|c|c|c|c|}
\hline Part number & Part geometry & Wall angle & $\begin{array}{l}\text { Part dimension } \\
(\mathrm{mm})\end{array}$ & $\begin{array}{l}\text { Heat treatment } \\
\text { before forming }\end{array}$ & $\begin{array}{l}\text { Heat treatment } \\
\text { after forming }\end{array}$ \\
\hline 1 & Elliptical draft & $15^{\circ}$ & $110 \times 60 \times 4.25$ & No & No \\
\hline 2 & Elliptical draft & $15^{\circ}$ & $110 \times 60 \times 4.25$ & Yes & No \\
\hline 3 & Elliptical draft & $15^{\circ}$ & $110 \times 60 \times 4.25$ & No & Yes \\
\hline 4 & Cranial implant & - & $105 \times 72 \times 19.86$ & No & No \\
\hline 5 & Cranial implant & - & $105 \times 72 \times 19.86$ & Yes & No \\
\hline 6 & Cranial implant & - & $105 \times 72 \times 19.86$ & No & Yes \\
\hline 7 & Truncated cone & $20^{\circ}$ & $110 \times 110 \times 17$ & No & No \\
\hline 8 & Truncated cone & $20^{\circ}$ & $110 \times 110 \times 17$ & Yes & No \\
\hline 9 & Truncated pyramid & $25^{\circ}$ & $112.5 \times 112.5 \times 13.5$ & No & No \\
\hline 10 & Truncated pyramid & $25^{\circ}$ & $112.5 \times 112.5 \times 13.5$ & Yes & No \\
\hline 11 & Truncated cone & $40^{\circ}$ & $110 \times 110 \times 17$ & No & No \\
\hline 12 & Truncated cone & $40^{\circ}$ & $110 \times 110 \times 17$ & Yes & No \\
\hline 13 & Truncated pyramid & $50^{\circ}$ & $112.5 \times 112.5 \times 13.5$ & No & No \\
\hline 14 & Truncated pyramid & $50^{\circ}$ & $112.5 \times 112.5 \times 13.5$ & Yes & No \\
\hline 15 & Elliptical draft & $30^{\circ}$ & $110 \times 60 \times 12.5$ & No & No \\
\hline 16 & Elliptical draft & $45^{\circ}$ & $110 \times 60 \times 22$ & No & No \\
\hline
\end{tabular}




\subsubsection{Tool contact side}

Table 2 lists the areal parameters on the tool contact side. The average roughness was observed to consistently improve with heat treatment done prior to forming for all the part geometries formed. In particular, the average roughness, Sa improved significantly for the elliptical draft $(0.650 \mu \mathrm{m}$ with heat treatment compared to $1.869 \mu \mathrm{m}$ without heat treatment) and cranial implant parts $(1.135 \mu \mathrm{m}$ compared to $6.744 \mu \mathrm{m})$. Figure 3 shows the height maps for the elliptical draft part while Fig. 5 shows the height maps for the cranial implant part. Corresponding to the visual appearance of no tool marks on parts formed with heat treatment prior to forming (as shown in Fig. 4 for the cranial implant), the height maps also show more areas in green indicating a smoother surface (see implant height maps in Fig. 5).

Sz was also seen to improve significantly for the elliptical draft and cranial implant parts, while it deteriorated for the conical part. The root mean square height also improved consistently for all parts. The skewness of the surfaces tends to be more negative with pre forming heat treatment. This indicates that there are more valleys than peaks in the heat treated parts. The kurtosis is also observed to increase with heat treatment. This indicates that the surface has more peaks if heat treated prior to forming. The fastest decay autocorrelation length is seen to decrease with pre forming heat treatment for all parts. The isotropy of the surface improves with pre-forming heat treatment for all parts except the elliptical draft.

Post-forming heat treatment was also seen to improve the average roughness. However, the maximum height of the surface deteriorated for the elliptical draft part. This can be attributed to the formation of a non-uniform layer of oxide film on the surface of the part (Fig. 3c provides indications of this). The root mean square height of the elliptical draft part also improved with heat treatment as did the skewness and kurtosis. The increase in skewness is in contrast with the part that was heat treated prior to forming where the skewness became negative. The skewness and kurtosis measures were reduced for the cranial implant part. The fastest decay autocorrelation length decreased significantly on heat treatment after forming, while the isotropy of the surface improved as a result of the heat treatment.

\subsubsection{Free surface}

The free surface had an average roughness of $1-3 \mu \mathrm{m}$ postforming for all the parts irrespective of heat treatment (see Table 3). This is higher than the $0.5-\mu \mathrm{m}$ average roughness that was measured for the sheets prior to forming, indicating that an orange peel effect can be observed for titanium just as was observed by Jeswiet et al. [12] for aluminum alloys. The average roughness is seen to improve only marginally as a result of heat treatment prior to forming. Figure 6 illustrates the case of the elliptical draft. There was a slight deterioration in average roughness for the conical part. In contrast, the maximum height was seen to improve significantly as a result of heat treatment for all parts other than the conical part. The root mean square height also improved as a result of heat treatment. No clear trend could be established for the skewness of the surface, while the kurtosis was seen to increase with heat treatment prior to forming. However, the kurtosis decreased with heat treatment post-forming, which was in contrast to the behavior of the surface in contact with the tool. In general, the free surface became more anisotropic as a result of preforming heat treatment and more isotropic with postforming heat treatment for the elliptical draft part.

For the cranial implant part, the average roughness, root mean square height, and maximum height increased as a result of post forming heat treatment. The skewness, fastest decay auto-correlation length, and kurtosis decreased, while the surface became more anisotropic compared to the part without any heat treatment.

Table 2 Areal surface topography parameters of formed parts on tool contact side

\begin{tabular}{llllllllll}
\hline Part geometry & $\begin{array}{l}\text { Heat treatment } \\
\text { before forming }\end{array}$ & $\begin{array}{l}\text { Heat treatment } \\
\text { after forming }\end{array}$ & Sa $(\mu \mathrm{m})$ & Sz $(\mu \mathrm{m})$ & Sq $(\mu \mathrm{m})$ & Ssk & Sku & Sal $(\mathrm{mm})$ & Str \\
\hline Elliptical draft & No & No & 1.869 & 53.864 & 2.401 & 0.230 & 6.102 & 0.115 \\
Elliptical draft & Yes & No & 0.650 & 18.431 & 0.846 & -0.426 & 7.540 & 0.114 & 0.392 \\
Elliptical draft & No & Yes & 0.926 & 74.926 & 1.362 & 0.726 & 25.612 & 0.013 & 0.707 \\
Cranial implant & No & No & 6.744 & 240.334 & 8.594 & 1.060 & 14.711 & 0.150 & 0.205 \\
Cranial implant & Yes & No & 1.135 & 57.221 & 1.795 & -1.093 & 18.249 & 0.004 & 0.707 \\
Cranial implant & No & Yes & 4.563 & 139.001 & 6.223 & 0.035 & 7.108 & 0.022 & 0.581 \\
Truncated cone & No & No & 2.036 & 17.612 & 2.606 & -0.430 & 3.365 & 0.122 & 0.334 \\
Truncated cone & Yes & No & 1.092 & 87.221 & 1.730 & -1.841 & 29.595 & 0.003 & 0.632 \\
Truncated pyramid & No & No & 1.203 & 67.783 & 1.748 & -0.118 & 16.289 & 0.007 & 0.358 \\
Truncated pyramid & Yes & No & 0.953 & 66.090 & 1.519 & -3.230 & 32.890 & 0.005 & 0.832 \\
\hline
\end{tabular}




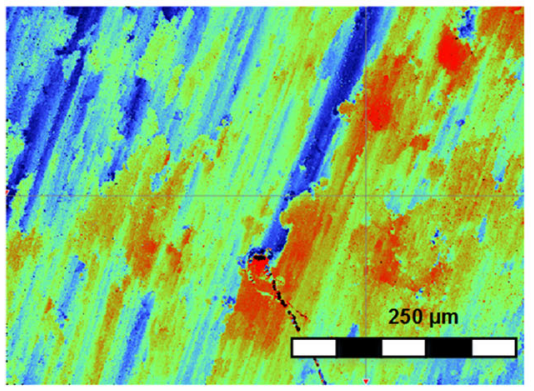

(a)

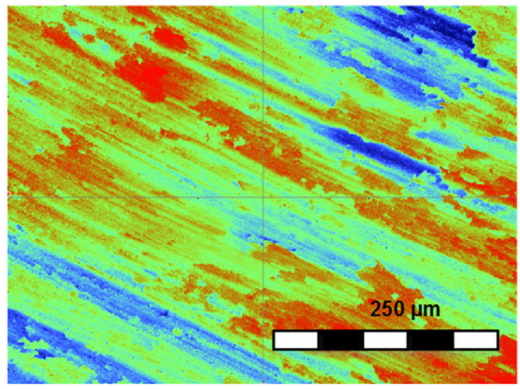

(b)

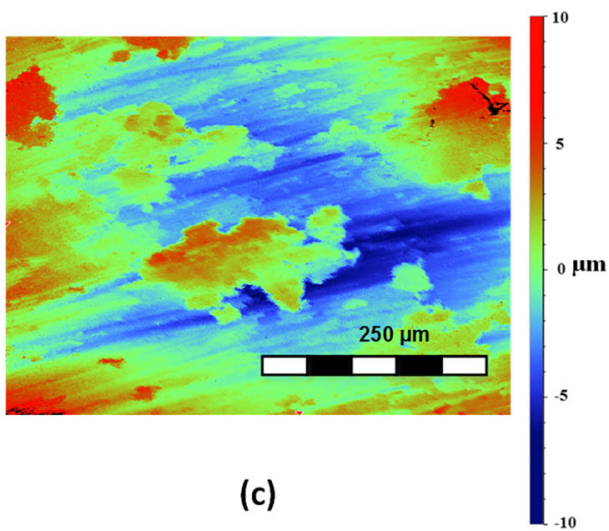

Fig. 3 Height maps of ellipse draft on tool contact side $\mathbf{a}$ no heat treatment $\mathbf{b}$ heat treatment before forming $\mathbf{c}$ heat treatment after forming

\subsection{Effect on accuracy}

\subsubsection{Accuracy of formed parts}

The formed parts were scanned using a Mitutoyo BRT Euro Apex 1200 co-ordinate measuring machine (CMM). The scanned point clouds were compared to the nominal computer-aided design (CAD) models of the parts, and the resulting deviations are presented as positive for under forming and negative for over forming. The results for the non-heat-treated parts showed that the forming of shallow wall angle parts, typically less than $30^{\circ}$ introduces large dimensional inaccuracies in the part post unclamping from the rig. This is illustrated in Fig. 7 for the elliptical draft part, where a maximum deviation of $5.33 \mathrm{~mm}$ was observed. This behavior can be explained by the fact that a shallow wall angle imparts a lower stiffness to the formed area as opposed to a high wall angle part, which is stiffer. The truncated pyramid also showed high dimensional deviations, while the truncated cone, which has an axi-symmetric geometry was more accurate with a maximum deviation of only $0.78 \mathrm{~mm}$ (Table 4). This indicates that the stiffness of the cone was higher than the pyramid as well as the elliptical draft.
For the elliptical draft part, the effect of heat treating the sheets before forming was to reduce the maximum deviations down to $2.14 \mathrm{~mm}$, an improvement of more than $3 \mathrm{~mm}$ over the non-heat-treated part (Fig. 8). A similar improvement was observed for the cranial implant (Fig. 9e, f), which is a freeform part, and the truncated cone (Fig. 9a, b), which is a ruled surface. However, for the truncated pyramid (Fig. 9c, d), a marginal deterioration in accuracy was observed, and the formed part had higher under formed areas as well as over formed areas. The improvement in accuracy for the ruled and freeform parts can be attributed to reduced residual stresses as a result of heat treatment. In contrast, the behavior of the pyramidal part can possibly be explained by the fact that the pyramidal part consists of planar features which are separated by stiff semi-vertical ribs. These ribs change the direction of the tool movement with respect to the direction in which the sheet has been rolled for every new planar face, and hence, the gains realized by the stress relieving heat treatment are offset by the processing of the part in two opposing directions, one parallel and the other transverse to the rolling direction.

Heat treatment after forming was also seen to have an effect on the accuracy of the parts. The maximum deviation in the elliptical draft part was observed to improve to $1.15 \mathrm{~mm}$. This
Fig. 4 Images of implants made using: a no heat treatment $\mathbf{b}$ heat treatment before forming showing zones with tool path step down $(1$ $3)$ and without step down $(2,4)$. The zone 3 has less visible step down marks compared with zone 1 while the zone 4 shows no tool path marks as opposed to zone 2 where the tool marks are still visible

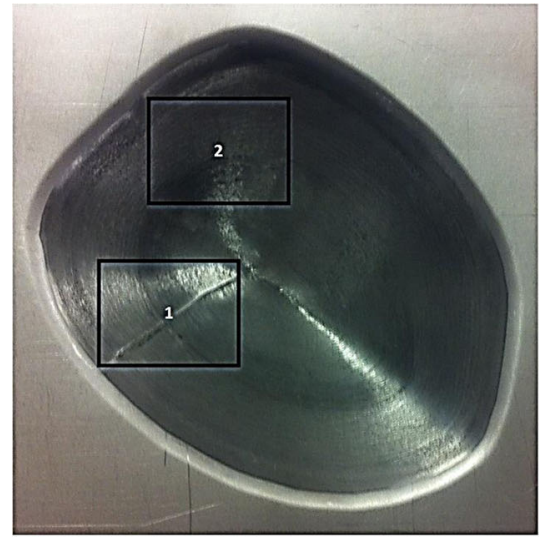

(a)

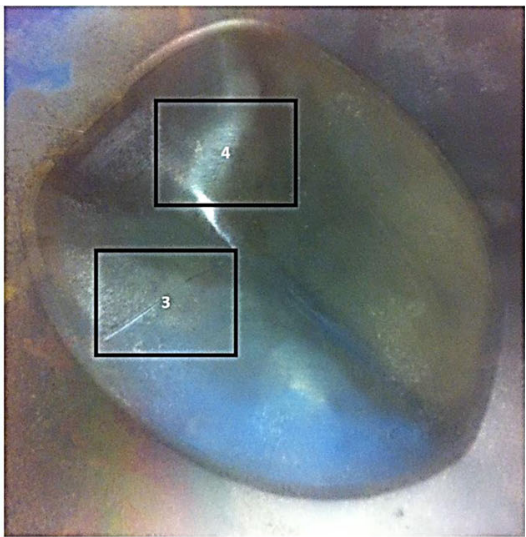

(b) 
Fig. 5 Height maps of cranial implant on tool contact side a no heat treatment $\mathbf{b}$ heat treatment before forming

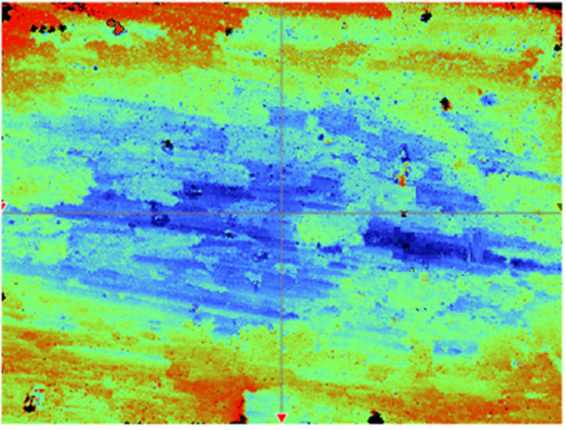

(a)

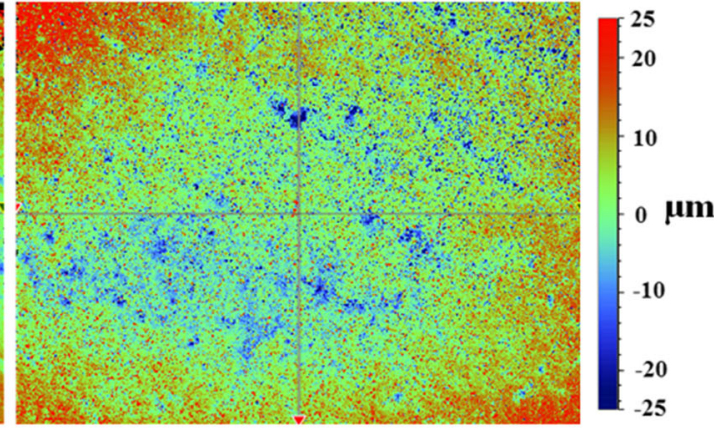

(b) indicates that distortion in the part shape caused due to residual stresses and low part stiffness which shows up on unclamping can be alleviated to a certain extent by using stress relieving heat treatment. Figure $8 \mathrm{c}$ shows the accuracy color plot of the part that was heat treated post forming. A similar improvement in accuracy was observed for the cranial implant part where the maximum deviation observed was $0.43 \mathrm{~mm}$ with a mean deviation of $0.02 \mathrm{~mm}$ and standard deviation of $0.16 \mathrm{~mm}$.

It may be noted that parts with higher wall angles $\left(40^{\circ}-50^{\circ}\right)$ with different geometries such as truncated cones and pyramids were also formed in this study and the accuracies with and without heat treatment was compared. In these parts, the magnitude of deviations close to the backing plate $(Z=0 \mathrm{~mm})$ was negligible as compared to the large magnitude of deviation that was observed in the low wall angle parts, which was illustrated earlier in Fig. 7. Hence, the effect of stress-relieving heat treatment in improving dimensional accuracy of parts is best observed in low wall angle parts, which tend to deform significantly close to the backing plate on unclamping the part from the rig used for incremental forming.

\subsubsection{Accuracy of trimmed parts}

Incrementally formed parts often need to be trimmed to the shape they are designed for. For instance, the cranial implant needs to be of the shape corresponding to the defect in the skull that is reconstructed. In such cases, the part has a tendency to deform due to the compressive residual stresses that are present in the specimen as a result of forming. This deformation can be significant, particularly for shallow wall angle parts. The results from the residual stress analysis, reported in section 3.4 indicated that stress relief heat treatment after forming reduced residual stresses to very small magnitudes. The parts were trimmed using metal cutting snips to observe the effect of this on trimming. To measure the shapes after trimming, a Dantec Q400 3D digital image correlation (DIC) system equipped with HILIS high-intensity light source and two 5 mega-pixel (MP) high-speed cameras was used. Figure 10 shows the results from the trimming studies, showing the trimmed parts and their accuracies. The implant part without stress relief heat treatment curled inwards due to the compressive stresses and has high dimensional inaccuracies when compared to the nominal CAD model of the implant. The curl up is in direction " 1 " where the compressive stresses are more than direction " 2 ." In contrast, the part that

Table 3 Areal surface topography parameters of formed parts on free surface

\begin{tabular}{llllllllll}
\hline Part geometry & $\begin{array}{l}\text { Heat treatment } \\
\text { before forming }\end{array}$ & $\begin{array}{l}\text { Heat treatment } \\
\text { after forming }\end{array}$ & Sa $(\mu \mathrm{m})$ & Sz $(\mu \mathrm{m})$ & Sq $(\mu \mathrm{m})$ & Ssk & Sku & Sal $(\mathrm{mm})$ & Str \\
\hline Elliptical draft & No & No & 1.840 & 67.294 & 2.446 & -0.493 & 6.738 & 0.265 & 0.553 \\
Elliptical draft & Yes & No & 1.580 & 57.754 & 2.115 & -0.954 & 7.554 & 0.238 & 0.512 \\
Elliptical draft & No & Yes & 1.418 & 48.665 & 1.827 & -0.366 & 4.979 & 0.373 & 0.743 \\
Cranial implant & No & No & 1.084 & 69.217 & 1.663 & 1.298 & 20.924 & 5.920 & 0.728 \\
Cranial implant & Yes & No & 1.067 & 55.882 & 1.657 & 1.289 & 21.981 & 4.412 & 0.620 \\
Cranial implant & No & Yes & 2.692 & 109.001 & 3.822 & 0.031 & 11.894 & 0.120 & 0.653 \\
Cone & No & No & 1.094 & 47.655 & 1.564 & 0.220 & 12.896 & 7.115 & 0.806 \\
Cone & Yes & No & 1.106 & 52.486 & 1.594 & 0.608 & 14.986 & 7.115 & 0.707 \\
Pyramid & No & No & 1.637 & 79.111 & 2.331 & -0.576 & 13.675 & 7.115 & 0.670 \\
Pyramid & Yes & No & 1.475 & 50.007 & 1.975 & 0.093 & 7.129 & 31.818 & 0.423 \\
\hline
\end{tabular}




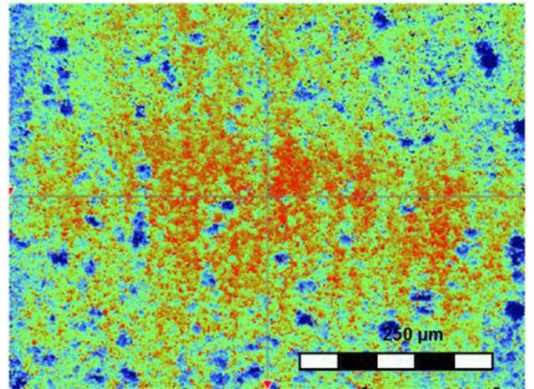

(a)

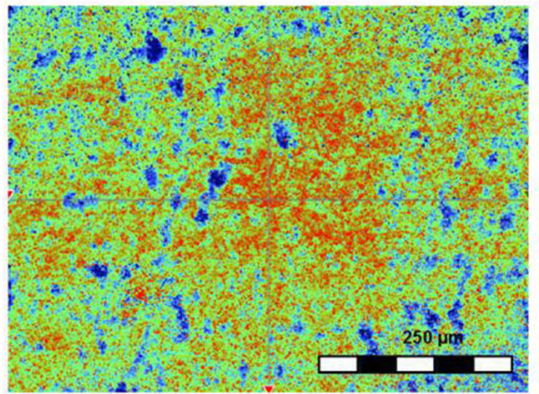

(b)

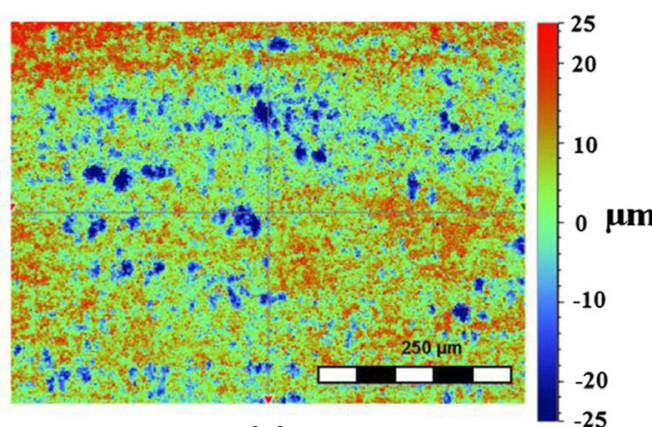

(c)

Fig. 6 Height maps of elliptical draft on free surface showing the result after $\mathbf{a}$ no heat treatment $\mathbf{b}$ heat treatment before forming $\mathbf{c}$ heat treatment after forming

underwent stress relieving after forming was nearly as accurate as it was in the untrimmed part geometry. These results are reported in Table 5.

\subsection{Surface topography imaging and EDX analysis}

Imaging of sample specimens taken from the formed parts was carried out using Philips XL30 fitted with a tungsten filament. An Oxford Instruments INCA microanalysis system fitted with a $\mathrm{Si}(\mathrm{Li})$ detector was used for energy-dispersive X-ray (EDX) elemental spectra and mapping. Secondary electrons (SE) were used to provide information about morphology and surface topography. This was followed by back scatter electron (BSE) imaging and EDX analysis to look at elemental compositions in sample specimens taken from the formed parts.

Figure 11 shows the results from the SE analysis. It was observed that the tool marks of individual contours are still visible in the specimens with no heat treatment (Fig. 11b and heat treatment done after forming (Fig. 11d). However, these tool marks are much less apparent in the specimen with heat treatment prior to forming (Fig. 11c). In this specimen, fine cracks are seen instead in the titanium oxide formed during the heat treatment. Moreover, the surface is smoother than the parts formed without heat treatment and with heat treatment after forming. The BSE imaging results, shown in Fig. 11, when combined with the EDX analysis reveal a presence of $\mathrm{Fe}$ in the sample taken from the part that was formed after heat treatment (Fig. 12f). This can be attributed to the increased hardness of the sheet after heat treatment and formation of an oxide layer as shown by da Rocha [32], which wears out the HSS tool to retain $\mathrm{Fe}$ on the formed plate. Specimens from the parts which were not heat treated show little or no presence of oxides and the oxygen $(\mathrm{O})$ peak is quite small in the EDX analysis (Fig. 12b, d). EDX mapping was carried out to find out the distribution of $\mathrm{Fe}$ in the sample which was heat treated prior to forming, and it was found that small concentrations $(<5 \mu \mathrm{m})$ can be observed scattered over the surface (Fig. 13). The SE images also revealed that the material is pushed around the sheet by the tool and deposited just before the tool step down to a new contour, which is consistent with the typical material flow behavior observed in incremental forming.

It may be noted that the cracks in the oxide layer that are observed for the parts heat treated prior to forming are visible only when seen under SEM. These cracks are not

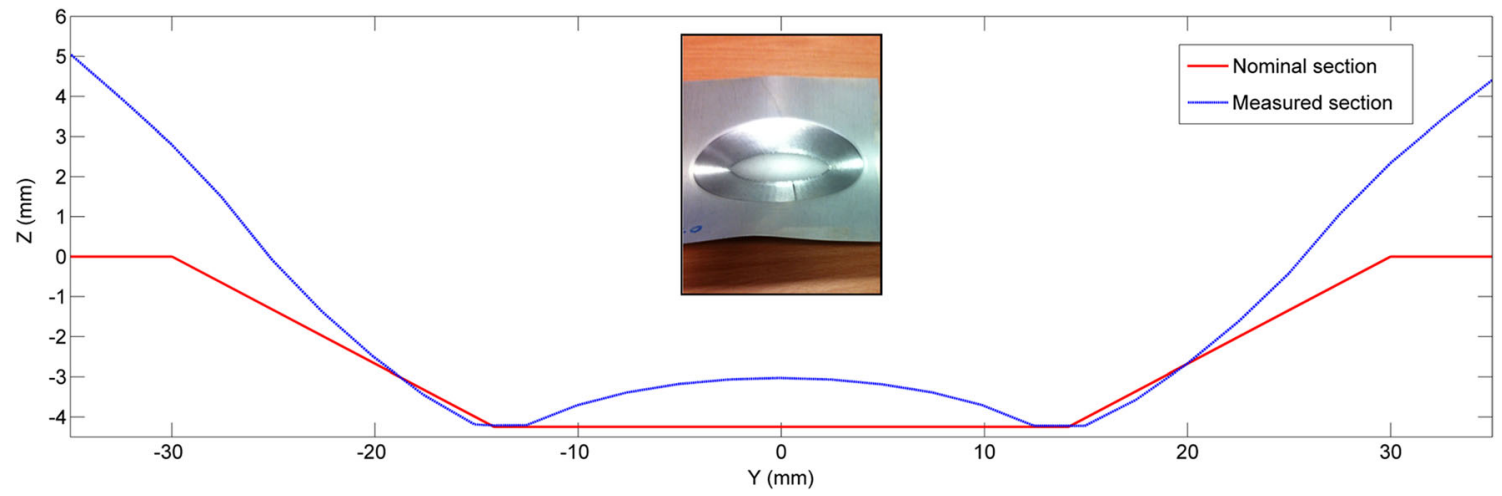

Fig. 7 Accuracy behavior of shallow wall angle titanium sheet parts formed without applying any heat treatment to the sheet illustrated using a crosssection views taken at $x=0$ along the minor axis; the manufactured part is shown inset 
Table 4 Accuracy behavior of titanium sheet parts

\begin{tabular}{|c|c|c|c|c|c|c|}
\hline Part geometry & $\begin{array}{l}\text { Heat treatment } \\
\text { before forming }\end{array}$ & $\begin{array}{l}\text { Heat treatment } \\
\text { after forming }\end{array}$ & Min. deviation (mm) & Max. deviation (mm) & Mean deviation (mm) & $\begin{array}{l}\text { Standard deviation } \\
(\mathrm{mm})\end{array}$ \\
\hline Elliptical draft & No & No & -4.14 & 5.33 & 0.17 & 1.62 \\
\hline Elliptical draft & Yes & No & -1.81 & 2.14 & 0.25 & 0.96 \\
\hline Elliptical draft & No & Yes & -1.65 & 1.15 & -0.23 & 0.51 \\
\hline Cranial implant & No & No & -0.47 & 1.02 & 0.09 & 0.24 \\
\hline Cranial implant & Yes & No & -0.31 & 0.81 & 0.07 & 0.19 \\
\hline Cranial implant & No & Yes & -0.39 & 0.43 & 0.02 & 0.16 \\
\hline Truncated cone & No & No & -0.2 & 0.78 & 0.37 & 0.21 \\
\hline Truncated cone & Yes & No & -0.61 & 0.30 & 0.00 & 0.19 \\
\hline Truncated pyramid & No & No & -1.41 & 3.37 & 0.09 & 0.84 \\
\hline Truncated pyramid & Yes & No & -1.82 & 4.73 & -0.13 & 1.00 \\
\hline
\end{tabular}

apparent to the naked eye. The most immediate visible effect of the heat treatment prior to forming was that the final surface did not contain the usual tool mark indentation that the incremental forming process leaves on the surface. It may be noted that the fine crack might affect the surface roughness which is a micro-scale effect, but the lack of tool mark indentations affects the surface roughness in a more pronounced manner, thereby reducing the average roughness that is measured. As the measurements support the visual appearance of a smooth surface, the conclusions of improvement in surface finish can therefore be validated.

\subsection{Residual stress measurements}

The XRD analysis of the formed parts was done using a Bruker AXS D8 Discover X-ray diffractometer fitted with $\mathrm{Cu}$ anode $\mathrm{X}$-ray tube with $\mathrm{Ni} \mathrm{K} \beta$-filter producing $\mathrm{Cu}-\mathrm{K} \alpha \mathrm{X}$ rays of wavelength $1.5406 \AA$ operating at $40 \mathrm{kV}$ and $30 \mathrm{~mA}$. The primary beam used focusing poly-capillary optics with 1.0-mm diameter long pinhole aperture while the secondary beam optics used 1.0-mm anti-scatter slit and 1.0-mm detector slit. The sample was mounted on a motorized stage on an Eulerian cradle and a scintillation X-ray detector was used. The three cranial implant parts were used for measurements. For each part, two separate scans were done. The first scan was a standard scan used to identify the phase compositions present in the sample by comparing against a benchmark plot of diffraction peaks for alpha-titanium and beta-titanium. The second scan was used to get a measure of the residual stress along two directions perpendicular to each other, labeled " 1 " and " 2 " as shown in Fig. 14. The measurements were performed at the bottom of the part, as this provided a flat region which was convenient for measurement.

For the standard scan, data was taken for the $2 \theta$ range $33^{\circ}$ to $160^{\circ}$ with a step of $0.1^{\circ}$ based on the expected peak values from the benchmark plots. Here, $\theta$ refers to the angular position of the diffraction lines according to Bragg's Law. Stress measurement was carried out as a series of diffraction scans of the $\alpha$-Ti (114) peak, scanning $2 \theta$ from $111.6^{\circ}$ to $116.8^{\circ}$ with a step size $0.05^{\circ}$ and step time $20 \mathrm{~s}$. The diffraction scans were collected with side-inclination angles corresponding to $\sin ^{2} \psi$ values from 0 to 0.75 in steps of 0.0833 , with the sample oriented to measure stress in two perpendicular directions in the sample surface. Here, $\psi$ refers to the angle between the normal of the sample and the normal of the diffracting plane.

The results of the standard XRD test indicated that the heat treated parts did not undergo any phase transformation from $\alpha$-Ti to $\beta$-Ti. Furthermore, these tests helped confirm the $2 \theta$ angle at which the stress measurements could be done. The general guideline for selecting the $2 \theta$ value is that it should be a large angle, typically exceeding $100^{\circ}$ and sufficiently removed from nearby peaks [33]. A high value of $2 \theta$ means that small changes in d-spacings due to strain can be measured precisely. Hence, the peak corresponding to Miller indices: $h=1, k=1, l=4$, was selected for residual stress measurements, which corresponds to a $2 \theta$ value of $114.2^{\circ}$.

Given that $\phi$ is the angle between a fixed direction in the plane of the sample and the projection in that plane of the normal of the diffracting plane, the strain measured in the direction of measurement defined by the angles $\phi$ and $\psi$ is given as below, following the procedure outlined by Cullity et al. [34]:

$d_{\phi \psi}=d_{0} \frac{1+\nu}{E} \sigma_{\phi} \sin ^{2} \psi-d_{0} \frac{\nu}{E}\left(\sigma_{11}+\sigma_{22}\right)+d_{0}$

where, $d_{0}$ is the strain free inter-planar spacing in the crystal lattice of the material, $d_{\phi \psi}$ is the inter-planar spacing of planes at an angle $\psi$ to the surface, $\nu$ is the Poisson's ratio for the material, $\sigma_{\phi}$ is the residual stress being measured in the direction given by the angle $\phi, \mathrm{E}$ is the Young's modulus, $\sigma_{11}$ and $\sigma_{22}$ are the principal stresses. 


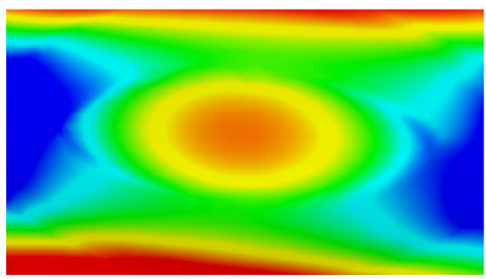

(a)

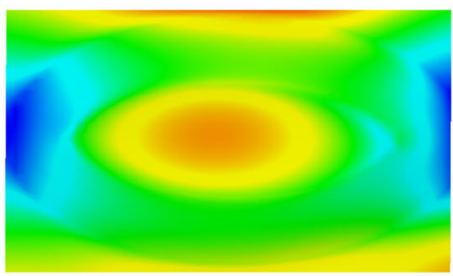

(b)

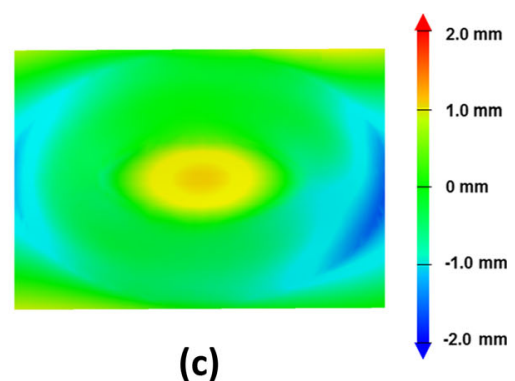

(c)

Fig. 8 Accuracy behavior of elliptical draft parts made a without heat treatment $\mathbf{b}$ heat treatment before forming $\mathbf{c}$ heat treatment after forming

Hence, $d_{\phi \psi}$ has a linear relationship with $\sin ^{2} \psi$, and the stress in the measurement direction, $\sigma_{\phi}$, can be calculated from the gradient of the relationship given the material constants $d_{0}, \nu$ and $E$. The raw diffraction patterns were processed by applying background subtraction, Lorentz-polarization correction, smoothing, and subtracting K- $\alpha_{2}$ contribution. The diffraction peak centers were determined by using the center-of-gravity method [33] with a $50 \%$ threshold.
The calculated residual stresses with the error margins are reported in Table 6. The results shows that for the cranial implant without heat treatment, the residual stresses in direction " 1 " are $54 \mathrm{MPa}$ higher than direction " 2 ." In comparision, the residual stresses in the implant part that underwent heat treatment prior to forming, has nearly symmetrical stresses in directions " 1 " and " 2 ," and the maximum stress magnitude is $32 \mathrm{MPa}$ less than the part without heat treatment. The implant

Fig. 9 Accuracy behavior of formed parts made: $\mathbf{a}, \mathbf{c}$, and $\mathbf{e}$ without heat treatment, $\mathbf{b}, \mathbf{d}$ and $\mathbf{f}$ with heat treatment before forming; Parts shown in $\mathbf{a}, \mathbf{b}$ are truncated cones, in $\mathbf{c}, \mathbf{d}$ are truncated pyramids and $\mathbf{e}, \mathbf{f}$ are cranial implants

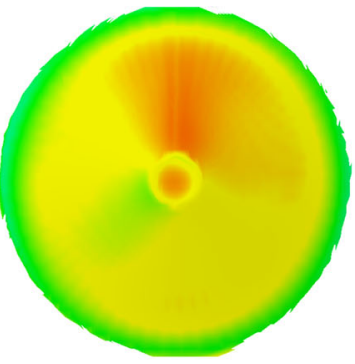

(a)

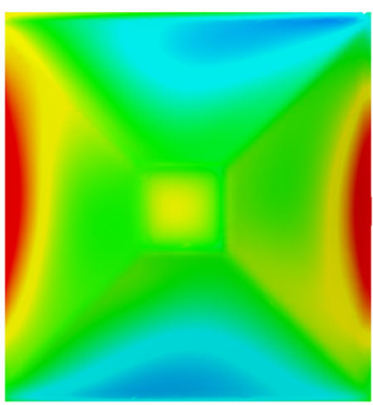

(c)

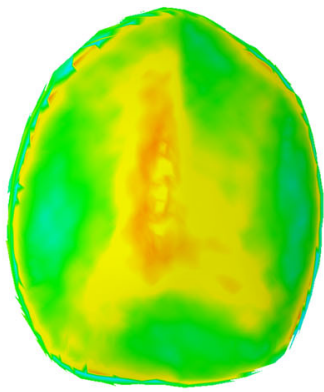

(e)

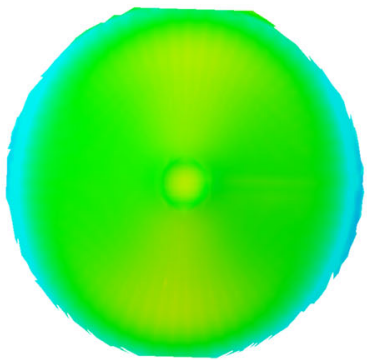

$1.0 \mathrm{~mm}$

$0.5 \mathrm{~mm}$

$0 \mathrm{~mm}$

$-0.5 \mathrm{~mm}$

(b)

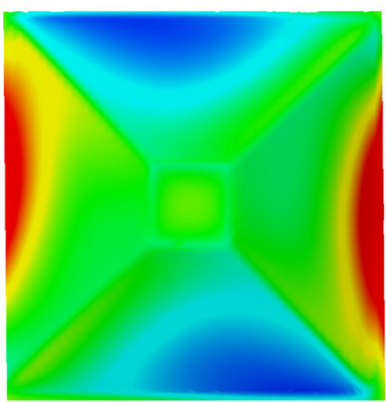

$1.0 \mathrm{~mm}$

$0 \mathrm{~mm}$

$-1.0 \mathrm{~mm}$

$-2.0 \mathrm{~mm}$

(d)

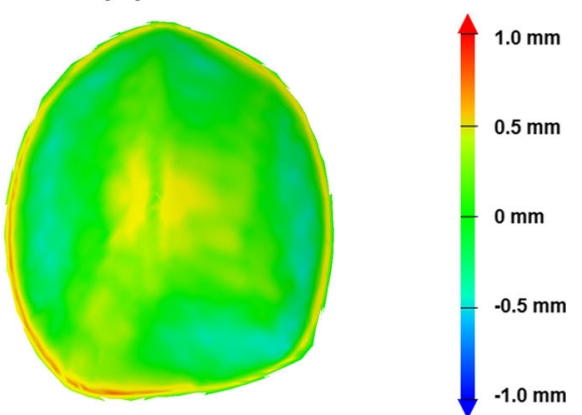

(f) 
Fig. 10 Effect of trimming on cranial implant parts: a non-heat treated $\mathbf{b}$ heat treated after forming; $\mathbf{c}$ and $\mathbf{d}$ show accuracy plots for parts above them; $\mathbf{a}$ and b show the surface patterned for DIC
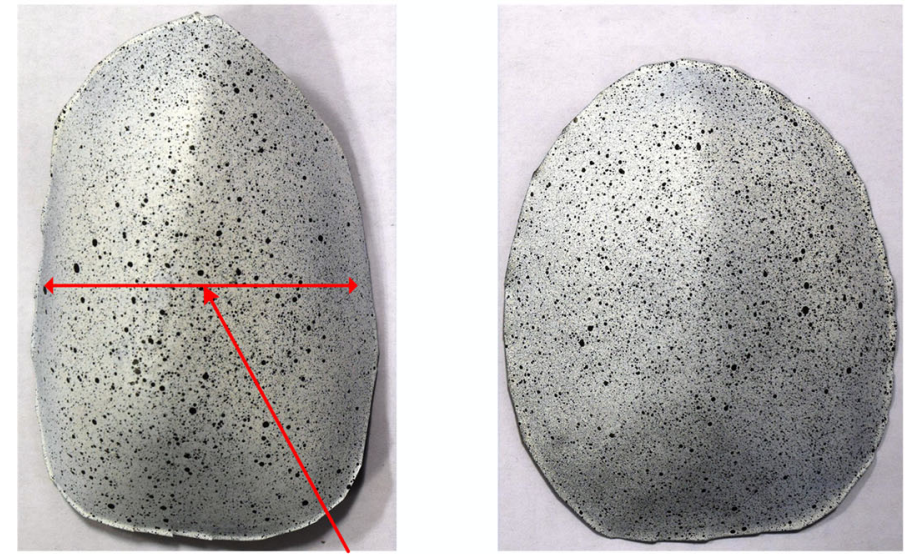

(a)

Direction of curl up on trimming

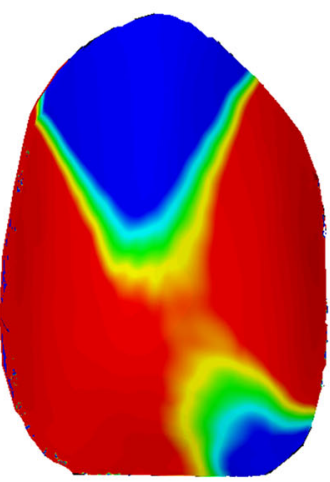

(c)

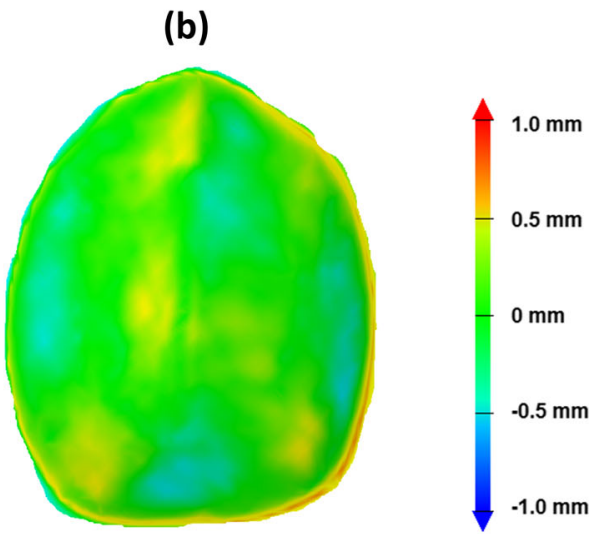

(d) part that underwent heat treatment after forming has almost negligible residual stresses, in comparision to the other two parts. These measurements explain the improvement in accuracy observed as a result of heat treatment, as reported in section 3.2.1. Furthermore, this has an important consequence for parts that need to be trimmed after forming, as discussed in Section 3.2.2.

\section{Underlying physical principles: discussion and recommendations}

The results from this research indicate that it is useful to carry out stress relieving heat treatment of titanium sheets in order to improve the surface roughness and dimensional accuracy of the final part. Sections 3.1 and 3.2 carried the results for the effects on surface finish and dimensional accuracy, while sections 3.3 and 3.4 contained a physical exploration of the causes behind the effects on surface finish and accuracy as explained by SEM imaging and XRD, which help understand the physical phenomena explaining these results. The XRD measurements further stimulated work on trimming the parts, which resulted in improvements in part accuracy, as explained in Section 3.2.2.

While the improvement in average surface roughness was found to be independent of the wall angles in the part geometry, as evidenced by the improvement observed in the wide selection of part geometries and wall angles in the studies conducted, the improvement in dimensional accuracy was limited to shallow wall angles and geometries without planar features. The independence of surface roughness on the wall angle can be explained by the fact that surface roughness is essentially dependent on the type of tribological contact that is established between the tool and the surface of the sheet material being formed and this contact determines the friction at the tool-sheet interface. As this contact is independent of the wall angle, the improvement in surface topography parameters with heat treatment does not depend on the slope of the part. However, the dimensional accuracy of the part is dependent on the wall angle, as illustrated by Behera et al. [16], where multivariate response surface models for part accuracy were developed as a function of the part wall angles. Furthermore, for shallow wall angle parts, the part distorts significantly after heat treatment close to the top surface at the level of the backing plate. Figure 15 shows the deviations at different wall 
Table 5 Accuracy results after trimming

\begin{tabular}{|c|c|c|c|c|c|c|}
\hline Part geometry & $\begin{array}{l}\text { Heat treatment } \\
\text { before forming }\end{array}$ & $\begin{array}{l}\text { Heat treatment } \\
\text { after forming }\end{array}$ & Min. deviation (mm) & Max. deviation (mm) & Mean deviation (mm) & $\begin{array}{l}\text { Standard } \\
\text { deviation } \\
(\mathrm{mm})\end{array}$ \\
\hline Cranial implant & No & No & -10.00 & 9.99 & -1.56 & 3.90 \\
\hline Cranial implant & No & Yes & -1.03 & 1.19 & -0.29 & 0.36 \\
\hline
\end{tabular}

angles for elliptical draft parts formed without any heat treatment where the major and minor axis diameters were varied. The deviations for the parts with wall angle of $15^{\circ}$ vary from 3.24 to $6.69 \mathrm{~mm}$, while for the parts with wall angle of $45^{\circ}$ vary from 0.19 to $1.27 \mathrm{~mm}$. Hence, the heat treatment procedures were more effective in improving the dimensional accuracy, as there was significant distortion due to residual stresses after unclamping the part from the rig used for SPIF.

It is noteworthy that there was a noticeable roughening effect on the free surface of the part, which points to an orange-peel effect as was observed in previous studies on aluminum alloys in the literature. This has now been confirmed for grade 1 titanium alloys as well, as a result of this study. There is a clear evidence of tool wear that occurs due to the increased hardness of the surface after heat treatment. This was indicated by the presence of Fe in the EDS analyses. The tool interacts with the titanium oxide layer present on the surface being formed and fine cracks can be seen on the surface in the SEM images as the tool wears the layer away. This interaction also means that the impression of the tool contours on the formed surface are either not present or barely present as the contour lines get imprinted on the oxide layer, which gets worn out. This underlying mechanism explains the forming of a smooth surface compared to forming of conventional non-heat-treated parts using SPIF.

The surface on the tool contact side became more isotropic with heat treatment both prior to and after forming for three of the four cases. However, on the free surface, the opposite effect was observed with the isotropy reducing for all four cases with heat treatment prior to forming, while for the elliptical draft part, the isotropy increased with heat treatment after forming. In addition, it was observed that with heat treatment prior to forming, the lay of the surface does not follow the contours of the toolpath and the formed surface blends into the unformed material. The formed surface lacks the typical burnishing seen in the parts formed without any heat treatment.

The average roughness on the free surface showed consistent improvement and the orange peel effect was much less prominent with heat treatment. As observed by Ham et al. [13] earlier, the orange peel effect can be
Fig. 11 Secondary electron imaging results showing a unprocessed Ti sheet, $\mathbf{b}$ part formed without undergoing any heat treatment, c part formed after heat treatment, $\mathbf{d}$ part that was heat treated post forming

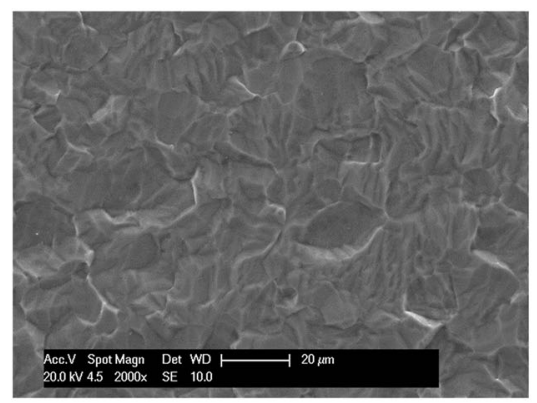

(a)

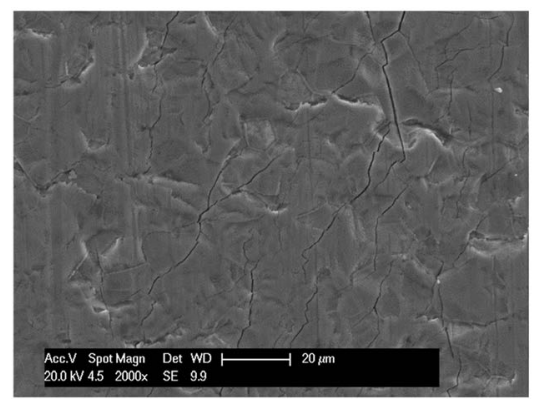

(c)

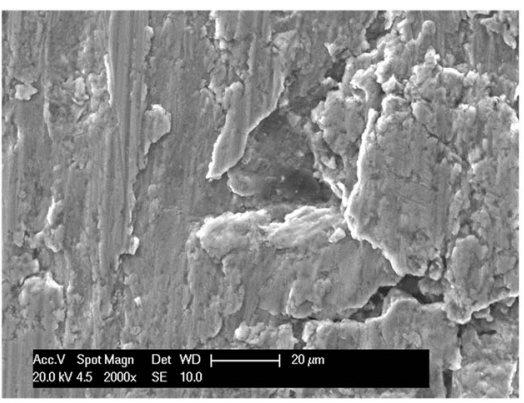

(b)

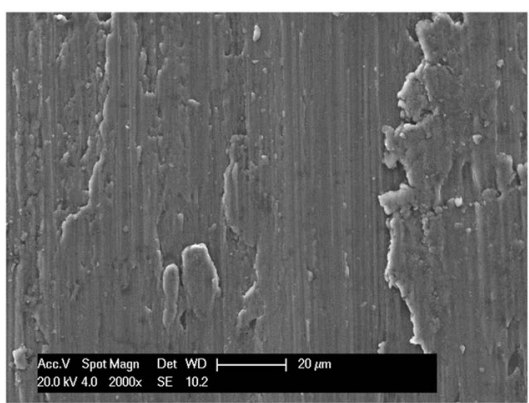

(d) 
Fig. 12 Back scatter electron imaging and EDX analysis results showing: a, b-unprocessed $\mathrm{Ti}$ sheet; c, $\mathbf{d}$ - part formed without undergoing any heat treatment; $\mathbf{e}$, f-part formed after heat treatment; $\mathbf{g}, \mathbf{h}$ - part that was heat treated post forming; the regions in the BSE images used for the EDX analysis are marked in pink and labeled as Spectrum 1, Spectrum 2, etc

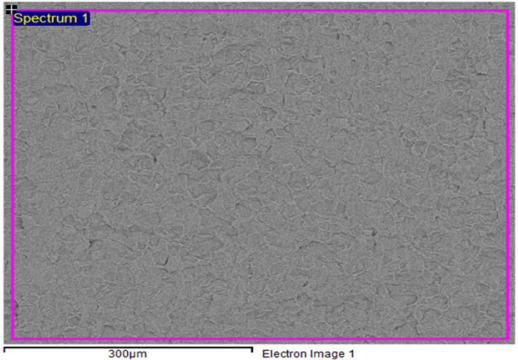

(a)

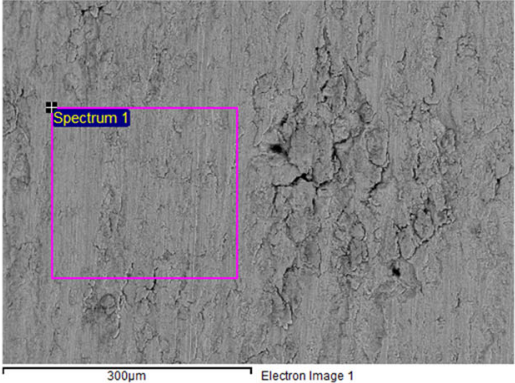

(c)

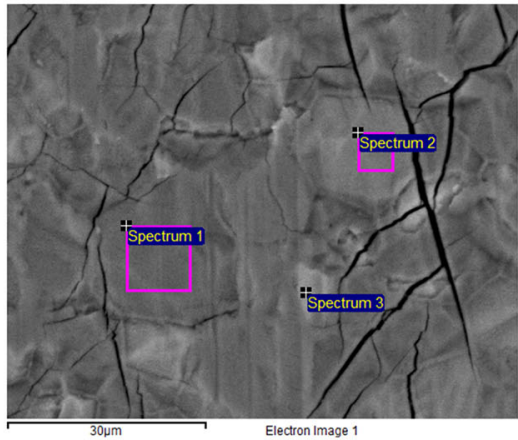

(e)

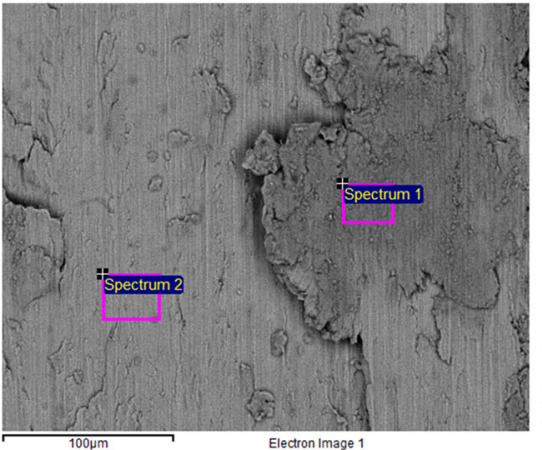

(g)

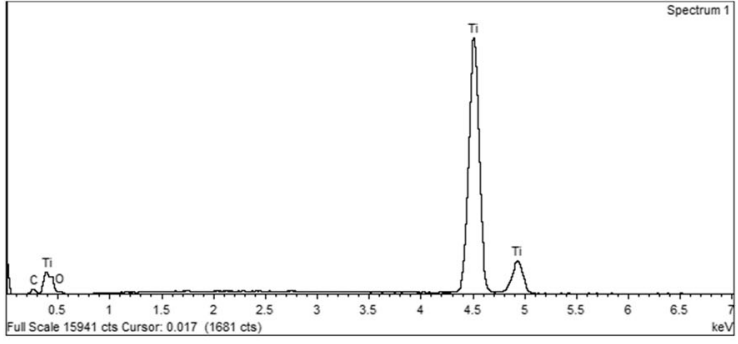

(b)

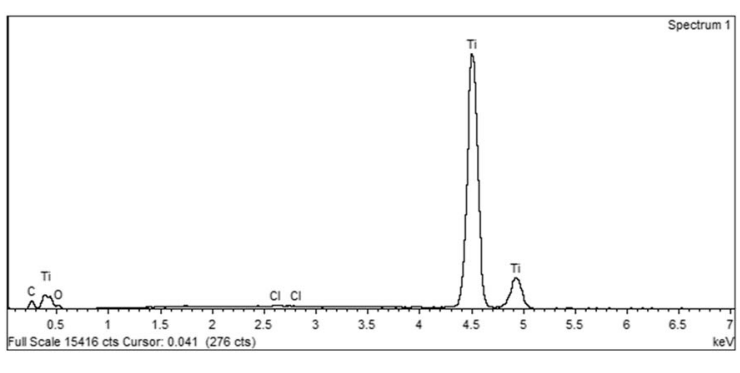

(d)

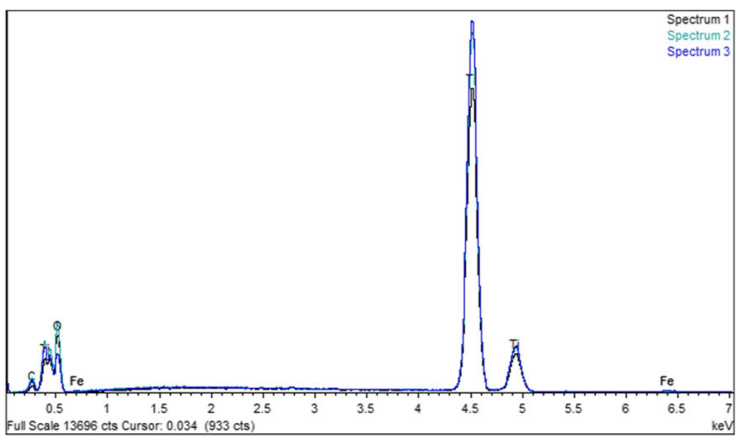

(f)

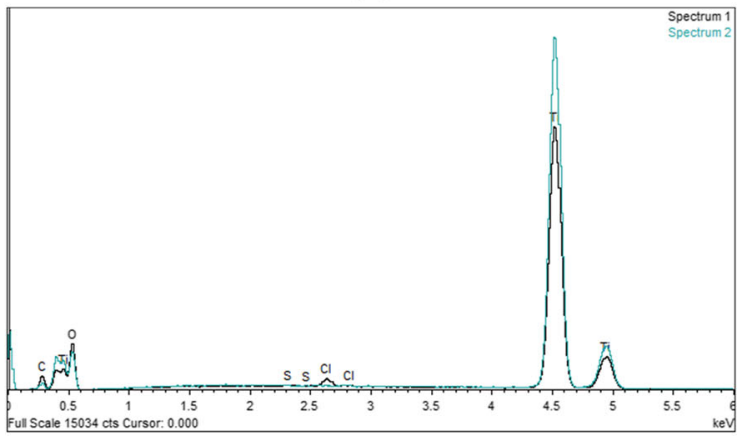

(h) attributed to the grain size and lattice structure. On subjecting the sheet to heat treatment, the increase in grain size results in an outer surface that has a reduced average surface roughness but higher anisotropy on forming. The dominant mechanisms for the resulting surface topography can be attributed to deformation twinning and grain slippage during SPIF.
The effect of the heat treatment on dimensional accuracy is best evident for parts that need to undergo trimming. In such cases, heat treatment after forming helps relieve compressive stresses and the trimmed parts are much more accurate than parts that have not undergone heat treatment. The final recommendations that emerge from the studies on surface roughness and dimensional deviations are that titanium sheet parts 
Fig. 13 EDX mapping on (a) specimen that was heat treated prior to forming; revealing small concentrations of $\mathrm{Fe}$ in the $\mathrm{Fe}$ map (d); in addition to an oxide layer in b-O map; c-Ti map
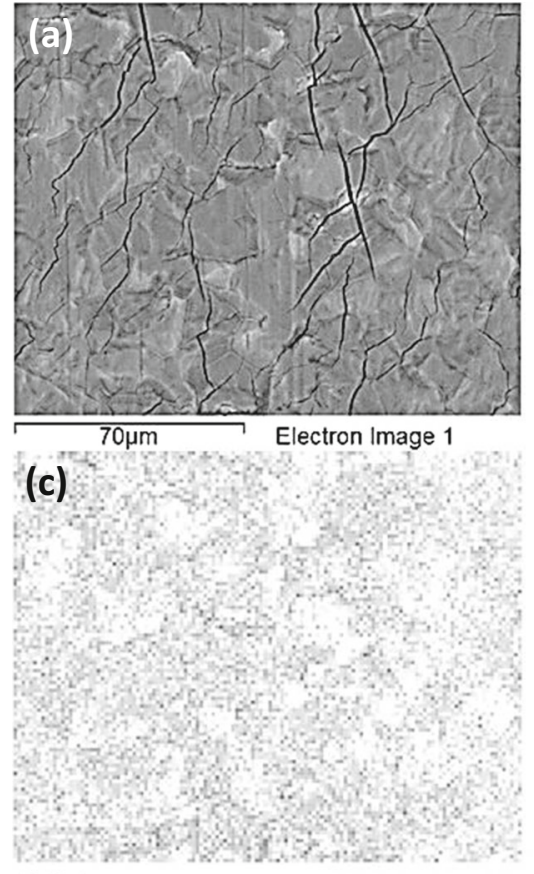

Tika1

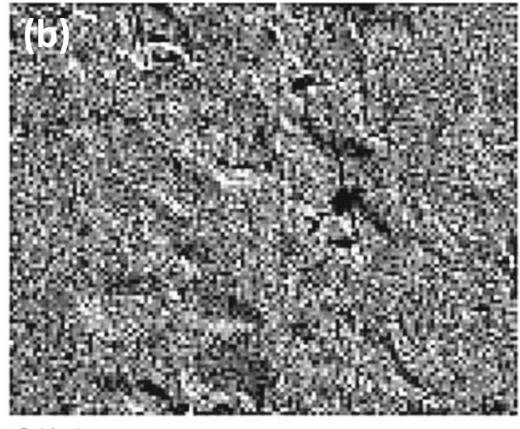

O Ka1

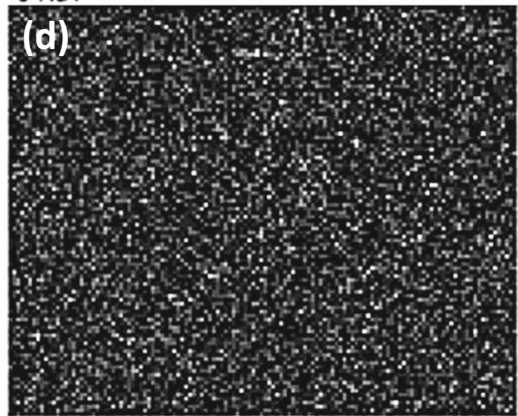

Fe Ka1 should be heat treated prior to forming, if surface roughness needs to be minimized while the formed parts should be stress relieved after forming, if the parts needs to be trimmed for use. Table 7 summarizes the overall effects of heat treatment on surface finish and accuracy.

\section{Conclusions and future work}

This study showed that stress relieving heat treatment of titanium sheets affects both the surface topography and the dimensional accuracy of parts formed using SPIF. Areal surface parameters were used to characterize the surface topography. Heat treatment prior to forming improved the average roughness for all the tested geometries on the tool contact side significantly. Minor improvement was also recorded on the free surface for three of the four geometries. Post-forming heat

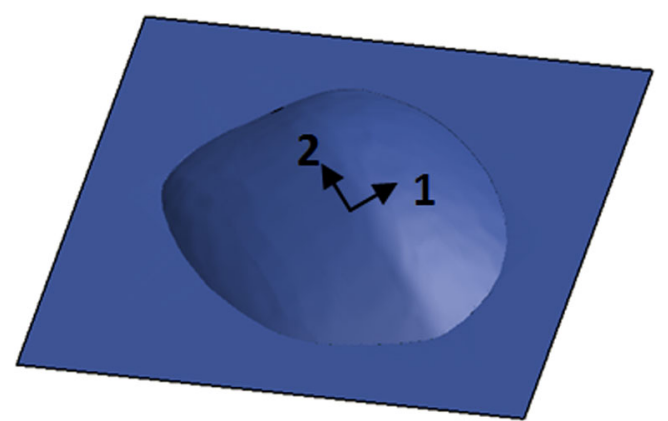

Fig. 14 Directions used for residual stress measurements by XRD treatment also improved the surface roughness for the elliptical draft part.

The dimensional accuracy of three of the four tested geometries consisting of ruled and freeform surfaces improved as a result of stress relieving heat treatment done prior to forming. However, the maximum and minimum deviations on the formed pyramid were higher as a result of the heat treatment. Post-forming heat treatment also improved the accuracy of the elliptical draft part. It was observed that the improvement is particularly significant for parts with shallow wall angles (typically $<25^{\circ}$ ). The improvement in maximum deviations for the shallowest part in the study, an elliptical draft part was more than $3 \mathrm{~mm}$. As the wall angle of the parts was increased, however, the improvement was less observable, as the accuracy of the part at the level of the backing plate was significantly better after unclamping the part from the rig.

Table 6 Residual stresses for the cranial implant parts

\begin{tabular}{llll}
\hline Direction & $\begin{array}{l}\text { Heat treatment } \\
\text { before forming }\end{array}$ & $\begin{array}{l}\text { Heat treatment } \\
\text { after forming }\end{array}$ & $\sigma_{\phi}(\mathrm{MPa})$ \\
\hline 1 & No & No & $-214.475 \pm 8.406$ \\
1 & Yes & No & $-182.322 \pm 34.188$ \\
1 & No & Yes & $-21.925 \pm 4.378$ \\
2 & No & No & $-160.409 \pm 10.641$ \\
2 & Yes & No & $-178.716 \pm 29.445$ \\
2 & No & Yes & $-6.832 \pm 7.268$ \\
\hline
\end{tabular}




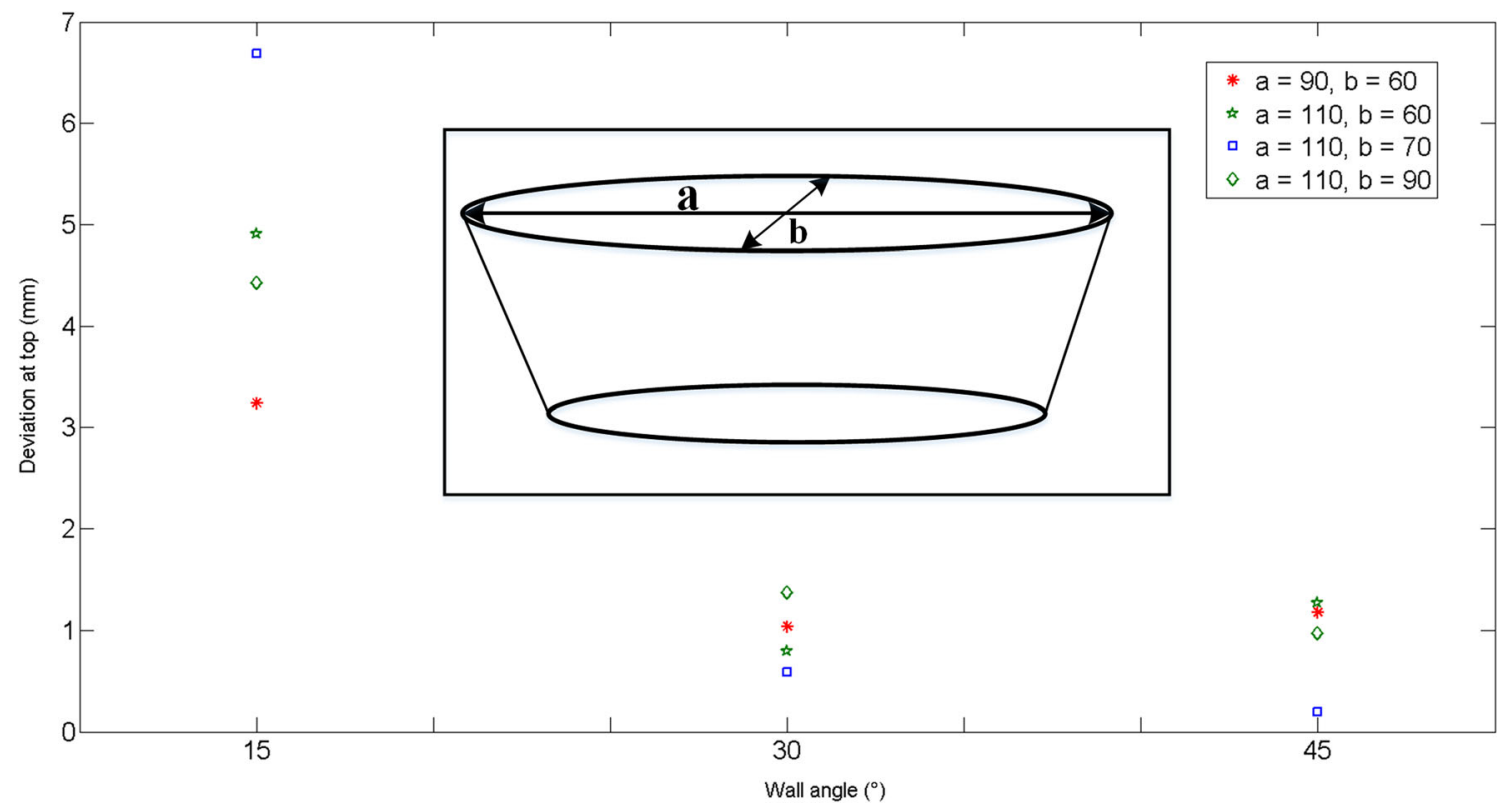

Fig. 15 Maximum deviation at the top of the part for elliptical draft parts with different wall angles and major and minor axis diameters (indicated as " $a$ " and " $b$ ")

Detailed topographical analysis was performed using scanning electron microscopy combined with energy dispersive Xray analysis. These studies indicated that the contour lines which are prominently visible in parts formed without heat treatment and in parts with heat treatment after forming are not visible in parts where heat treatment is done prior to forming. However, it was interesting to observe that traces of $\mathrm{Fe}$ were found on the parts with heat treatment performed prior to forming. This is due to the increased hardness of the part surface and formation of an oxide layer during heat treatment, which wears out the tool material.

Residual stress measurements indicated that the parts that underwent heat treatment before forming had symmetrical stress magnitudes in two directions perpendicular to each other, and the maximum stress magnitude was lower than parts that did not undergo heat treatment. Furthermore, the parts that were heat treated after forming had almost negligible residual stresses in them. Hence, these parts did not curl inwards on trimming the desired shape from the formed part, while the part without heat treatment curled inwards. This presents a useful solution for part trimming after incremental forming, where stress relieving heat treatment helps form usable parts in real life applications such as medical implants.

Further studies extending this research can be conducted to study the effect of the tool material on the surface roughness of titanium parts, effect of lubricant and process parameters such as feed rate, tool diameter, and step down. In particular, although the surface finish of parts can be improved using controlled heat treatment, there is a need to look at tool wear from the increased hardness. Further studies can include investigating the possible use of improved lubrication strategies or modifying the surface post-heat treatment that would minimize tool wear. The choice of appropriate tools and surface coatings on tools that help improve surface finish of heat treated sheets that are formed using incremental forming is also worthy of investigation. The influence of parameters of the tool such as tool rotation, geometrical shape, stiffness and roughness, and the interaction between the sheet material, tool, and process parameters can be the subject of future investigations. It would also be useful to build models that allow for careful control of the surface topography which is critical for many applications.

Table 7 Summary of effects of heat treatment on surface finish and accuracy

\begin{tabular}{llllll}
\hline $\begin{array}{l}\text { Heat treatment } \\
\text { before forming }\end{array}$ & $\begin{array}{l}\text { Heat treatment } \\
\text { after forming }\end{array}$ & $\begin{array}{l}\text { Surface finish } \\
\text { (tool contact) }\end{array}$ & Surface finish (free surface) & $\begin{array}{l}\text { Dimensional accuracy } \\
\text { before trimming }\end{array}$ & $\begin{array}{l}\text { Dimensional accuracy } \\
\text { after trimming }\end{array}$ \\
\hline No & No & - & - & - & - \\
No & Yes & + & $\sim$ & ++ & ++ \\
Yes & No & ++ & + & + & + \\
\hline
\end{tabular}

- Extremely poor, - poor, little or no effect, + modest improvement, ++ significant improvement 
Acknowledgments This work was supported by the Engineering and Physical Science Research Council of UK (EP/L02084X/1), International Research Staff Exchange Scheme (IRSES, MatProFuture project, 318,968 ) within the seventh EC Framework Programme (FP7). The authors acknowledge the help provided by Dr. Nigel Neate, Ben Shaw, Tom Buss, John Hinchliffe, and Mark Daine in the faculty workshop and materials processing facilities.

Open Access This article is distributed under the terms of the Creative Commons Attribution 4.0 International License (http:// creativecommons.org/licenses/by/4.0/), which permits unrestricted use, distribution, and reproduction in any medium, provided you give appropriate credit to the original author(s) and the source, provide a link to the Creative Commons license, and indicate if changes were made.

\section{References}

1. Krebs RE (2006) The history and use of our earth's chemical elements: a reference guide, 2nd edn. Greenwood Press, Westport

2. Bannon B, Mild E (1983) Titanium alloys for biomaterial application: an overview. Titanium alloys in surgical implants. ASTM STP 796:7-15

3. Donachie MJ (2000) Titanium: a Technical Guide. 2nd edn. ASM International, Materials Park, Ohio

4. Nishiguchi S, Nakamura T, Kobayashi M, Kim HM, Miyaji F, Kokubo T (1999) The effect of heat treatment on bone-bonding ability of alkali-treated titanium. Biomaterials 20(5):491-500

5. Wennerberg A, Albrektsson T (2000) Suggested guidelines for the topographic evaluation of implant surfaces. Int J Oral Maxillofac Implants 15(3):331-344

6. Wennerberg A, Albrektsson T, Andersson B (1995) Bone tissue response to commercially pure titanium implants blasted with fine and coarse particles of aluminum oxide. Int $\mathbf{J}$ Oral Maxillofac Implants 11(1):38-45

7. Jeswiet J, Micari F, Hirt G, Bramley A, Duflou J, Allwood J (2005) Asymmetric single point incremental forming of sheet metal. Cirp Ann-Manuf Technol 54(2):623-649

8. Behera AK (2013) Shape Feature Taxonomy Development for Toolpath Optimisation in Incremental Sheet Forming. PhD Thesis. Katholieke Universiteit Leuven ISBN 978-94-6018-733-9

9. Behera AK, Lauwers B, Duflou JR (2013) Tool path generation for single point incremental forming using intelligent sequencing and multi-step mesh morphing techniques. Int J Mater Form 8(4):517532. doi:10.1007/s12289-014-1174-y

10. Kurra S, Rahman NH, Regalla SP, Gupta AK (2015) Modeling and optimization of surface roughness in single point incremental forming process. J Mater Res Technol 4(3):304-313. doi:10.1016/ j.jmrt.2015.01.003

11. Ham M, Powers B, Brown C, Jeswiet J, Hamilton K (2009) Roughness evaluation of single point incrementally formed surfaces. Trans NAMRI/SME 37:411-418

12. Hamilton K, Jeswiet J (2010) Single point incremental forming at high feed rates and rotational speeds: surface and structural consequences. Cirp Ann-Manuf Technol 59(1):311-314

13. Ham M, Powers BM, Loiselle J (2013) Surface topography from single point incremental forming using an acetal tool. Key Eng Mater 549:84-91

14. Ham M, Powers BM, Loiselle J (2014) Multiscale analysis of surface topography from single point incremental forming using an acetal tool. J Phys 483:012008
15. Behera AK, Lauwers B, Duflou JR (2014) Tool path generation framework for accurate manufacture of complex 3D sheet metal parts using single point incremental forming. Comput Ind 65(4):563-584

16. Behera AK, Verbert J, Lauwers B, Duflou JR (2013) Tool path compensation strategies for single point incremental sheet forming using multivariate adaptive regression splines. Comput Aided Des 45(3): $575-590$

17. Malhotra R, Reddy NV, Cao JA (2010) Automatic 3D spiral toolpath generation for single point incremental forming. J Manuf Sci E-T Asme 132(6): 1-10

18. Essa K, Hartley P (2011) An assessment of various process strategies for improving precision in single point incremental forming. Int J Mater Form 4(4):401-412

19. Duflou JR, Callebaut B, Verbert J, De Baerdemaeker H (2007) Laser assisted incremental forming: formability and accuracy improvement. Cirp Ann-Manuf Technol 56(1):273-276

20. Fan GQ, Gao L, Hussain G, Wu ZL (2008) Electric hot incremental forming: a novel technique. Int J Mach Tools Manuf 48(15):16881692

21. Verbert J, Duflou JR, Lauwers B (2007) Feature based approach for increasing the accuracy of the SPIF process. Key Eng Mater 344: 527-534

22. Lu B, Chen J, Ou H, Cao J (2013) Feature-based tool path generation approach for incremental sheet forming process. J Mater Process Technol 213(7):1221-1233. doi:10.1016/j.jmatprotec.2013.01.023

23. Malhotra R, Cao J, Ren F, Kiridena V, Xia ZC, Reddy NV (2011) Improvement of Geometric Accuracy in Incremental Forming by Using a Squeezing Toolpath Strategy With Two Forming Tools. J Manuf Sci E-T Asme 133(6):061019. doi:10.1115/1.4005179

24. Göttmann A, Korinth M, Schäfer V, Araghi BT, Bambach M, Hirt G (2013) Manufacturing of individualized cranial implants using two point incremental sheet metal forming. In: Schuh G, Neugebauer R, Uhlmann E (eds) Future trends in production engineering. Springer, Berlin Heidelberg, pp 287-295

25. Duflou JR, Behera AK, Vanhove H, Bertol LS (2013) Manufacture of accurate titanium cranio-facial implants with high forming angle using single point incremental forming. Key Eng Mater 549:223-230

26. ASM Metals Handbook, Volume 4, Heat Treating (1991) ASM International, Materials Park, Ohio

27. Semiatin SL, Seetharaman V, Weiss I (1997) The thermomechanical processing of alpha/beta titanium alloys. Jom J Miner Met Mater Soc 49(6):33-39

28. Behera AK, Lu B, Ou H (2015) Characterization of shape and dimensional accuracy of incrementally formed titanium sheet parts with intermediate curvatures between two feature types. Int J Adv Manuf Technol 83(5):1099-1111

29. Lu B, Ou H, Shi S, Long H, Chen J (2014) Titanium based cranial reconstruction using incremental sheet forming. Thematic Issue: Flexible Forming - Incremental Sheet Forming \& Roll Forming. Int J Mater Form:1-10. doi:10.1007/s12289-014-1205-8

30. ISO 25178: Geometrical product specifications (GPS) - Surface texture: Areal (2012) International Organisation for Standardisation

31. Welcome to Vision64 (2012) User Manual, Bruker Corporation

32. da Rocha SS, Adabo GL, Henriques GE, Nobilo MA (2006) Vickers hardness of cast commercially pure titanium and Ti-6Al4V alloy submitted to heat treatments. Braz Dent J 17(2):126-129

33. Fitzpatrick ME, Fry AT, Holdway P, Kandil FA, Shackleton J, Suominen L (2005) Determination of Residual Stresses by Xray Diffraction - Issue 2. Measurement Good Practice Guide No. 52. National Physical Laboratory. http://www.npl.co.uk/ upload/pdf/Determination_of_Residual_Stresses_by_X-ray_ Diffraction - Issue 2.pdf. Accessed 31 Mar 2016

34. Culity B, Stock S (2001) Elements of X-ray Diffraction, 3rd edn. Prentice Hall, Upper Saddle River 